\title{
Environmental Management of Shale Gas Development in China: Status and Challenges
}

\author{
Guihua Zheng ${ }^{1,2}$, Linghui Deng², Xiaonan Feng ${ }^{1, *}$, Jing Sun ${ }^{2}$, Yixin Lu $^{2}$, Yiyi Yang ${ }^{2}$, Jiacheng Shi², \\ Juzhen $\mathrm{Wu}^{2, * *}$ \\ ${ }^{1}$ School of Environmental Science and Engineering, Huazhong University of Science and Technology, Wuhan, China \\ ${ }^{2}$ School of Materials and Environmental Engineering, Chengdu Technological University, Chengdu, China \\ Email address: \\ zjw_77@163.com (Guihua Zheng), 1742664379@qq.com (Linghui Deng), xn feng@hust.edu.cn (Xiaonan Feng), \\ 879157142@qq.com (Jing Sun), 460098192@qq.com (Yixin Lu),1576740789@qq.com (Yiyi Yang), 1243439308@qq.com (Jiacheng Shi), \\ 403141272@qq.com (Juzhen Wu) \\ ${ }^{*}$ Corresponding author
}

\section{To cite this article:}

Guihua Zheng, Linghui Deng, Xiaonan Feng, Jing Sun, Yixin Lu, Yiyi Yang, Jiacheng Shi, Juzhen Wu. Environmental Management of Shale Gas Development in China: Status and Challenges. International Journal of Environmental Protection and Policy. Vol. 9, No. 1, 2021 , pp. 1-4. doi: 10.11648/j.ijepp.20210901.11

Received: November 28, 2020; Accepted: January 12, 2021; Published: January 22, 2021

\begin{abstract}
Shale gas, as a clean energy, can save and substitute for a lot of coal and oil resource, reduce carbon emissions and further improve ecological environment. However, gas shale exploration has led to cause environmental issues such as air pollution, water pollution and ecological destruction etc., Through the method of literature study, social investigation and systematic analysis, the main challenges for the shale gas exploitation were studied, including the research on environmental impact of the shale gas development is not deep enough, pollution control technologies are still immature, and development techniques for deep shale gas aren't master yet. The environmental management practices of shale gas development were systematically sorted out. First, strengthening basic research and key technologies tackling. Second, optimizing development planning and sequence of shale gas, promoting strategic environmental impact assessment and planning environmental impact assessment, the third, clarifying the management ideas and system of environmental impact assessment (EIA) and strengthen EIA supervision. The main problems still to be solved in the environmental protection of shale gas development, advices on both technical and management will be proposed, and it will offer experience for the shale gas exploring in China.
\end{abstract}

Keywords: Shale Gas, Environmental Impact Analysis, Countermeasure, Environmental Problem

\section{The Present Status of Shale Gas Development}

Through technology breakthrough and exploration during the Twelfth Five-Year Plan period, breakthroughs have been obtained on key technologies used for the exploration and development of shale gas, engineering equipment has realized the localization, some important progress has been made on the base of basic geological investigation, Large numbers of shale gas wells were confirmed to have good resources and great potential in Ordos Basin and Sichuan basin and its surroundings, About ten favorable target areas were delineated, some important lessons was achieved on policy support, international cooperation and the related management of shale gas mining rights, China has already mastered the technology involved in shallow-sea shale gas exploration below 3500 meters, which effectively support the healthy and rapid development of the shale gas industry $[1,2]$.

As the increasingly intensify of air pollution control, China vigorously pursued the clean, low-carbon development strategy and actively advanced new urbanization infrastructure construction, natural gas will play a greater role to adjust and optimize the structure of energy source, our national development strategy and guide of policy provide the broad space for he development of shale gas. Important breakthroughs were achieved in marine shale gas exploration in southern China. Shale gas of Sichuan Basin has realized large-scale and the commercial development in China, lots of other favorable areas acquired industrial testing equipment 
flow, marine shale gas resource of Longma stream has great potential in southern China, and it was confirmed strongly. Rich resource and good industry startup provided the solid safeguard for shale gas development $[3,4]$.

\section{The Key Issues and Challenge in Shale Gas Development}

China's new normal of economic development actively will promote the adjustment and optimization of energy structure, with the increasing demand for nature gas and other clean energy, and this provided precious strategic opportunities for the large-scale development of shale gas. While China's shale gas industry is still at the beginning stage, there are many impacts of uncertainties and more risk factors. However, most of shale gas resources are low-grade and well dispersive with more development difficulties, compared with the conventional natural gas, and its environment impact has several obvious characteristics.

\subsection{Environmental Impact}

Lots of drilling will cause land occupation and significant ecological environmental impacts. However large numbers of drilling are necessary for shale gas output scale, drillers number is about hundreds of times more than the conventional natural gas, well-field covers more than 10 times area, it takes lots of lands. Shale gas development will affect surface ecology and the environment, and groundwater resources will be disturbed. the conflict between agriculture, ecology, agricultural land and shale gas should be taken notice. Water consumption used for shale gas exploration is about ten times more than its conventional natural gas, and water resource stress and severe water pollution caused by large water consumption are especially evident [5].

The composition of wastewater from shale gas industry is complex, which contains large amount of heavy metal, salt and radioactive material and more than one hundred kinds of chemicals. shale gas favorable areas are largely located in Sichuan, Chongqing, Hunan and Guizhou provinces, the geologic conditions are complicated, underground river and underground caverns are numerous, it is difficult to prevent and control underground water pollution $[6,7]$. Gas industry is the major source of methane, volatile organic compound and other harmful air pollutants. Shale contains high concentration of hydrogen sulfide in China, it may do harm to people and partial air quality if not disposed well $[8,9]$. Compared with the conventional natural gas, greenhouse gases, methane leaks are much riskier, and the influences of shale gas development on air quality and climatic changes can't be ignored, while how shale gas development affects the surface water environment, groundwater, regional geological and to what extent it may influence the environment, no definite conclusion has been given yet.

\subsection{Pollution Control Technology}

A large amount of wastewater and drilling solid waste were discharged in shale gas development process, especially the produced water and drilled cuttings have been the key and difficult points in pollution control. Shale gas development is still in the initial stage in China. Because of the specificity of produced water and drilled cuttings, reasonable economically processing technology is still in the progress of research and exploring, and it brings tremendous challenges to environmental management. Basic research, applying basic research should be carried out about environmental impact and green technology, which help to solve the key and difficult problem, such as pollution control, clean production etc., promote the transformation of technological achievements and the promotion and application of advanced technology, the research production can provide technology guarantees, decision support and intellectual support for the environmental management of shale gas development $[10,11]$. The existing technology couldn't determine whether some of the environmental issues relates to shale gas exploitation, more complaints comes from the general public, which posed some serious challenges for environmental regulation and handling complaints.

\subsection{Development Techniques for Deep Shale Gas}

Exploiting underground shale gas at the 3,500 m depth demands higher horizontal drilling technique, fracturing technology and the equipment. And more than half shale gas resources were more than 3,500 m under ground, which was the focus of construction and operation in South Sichuan, whether this part could effectively develop, which will affect the scale of shale gas resources in China in 13th Five-Year period.

\section{Suggestions and Countermeasures}

Environmental standards related to shale gas development should be set on the basis of strictly compliance with Environment Protection Act and and other related laws and regulations. Factory production of horizontal wells should be widely promoted, it is necessary to reduce the number of well sites, decrease the occupied area of land, and carry out vegetation restoration for abandoned well sites. Methane gas should be strictly recycled in production, or methane pollution prevention and treatment should be conducted if not qualified for recycling. Flow back of fracturing fluid will be recycled or treated harmless in the process of yield increase and renovation to reduce the discharged pollutants [12-14].

\subsection{Strengthening Basic Research and Key Technologies Tackling}

It is important to accelerate the research and application of pollutant disposal technology, carry out researches on comprehensive utilization technology of drilling solid wastes, the overall solution of waste water recycling and standardized discharge, and the measures to reduce carbon emission in gas testing and flow back process, and it is necessary to conduct the research and application of new 
technology for shallow layer leakage prevention, formulate quota index of fresh water consumption in fracturing process, improve the repetitive utilization rate of fracturing fluid and flow back solution, and it is critical to develop scientific research for anhydrous or water-saving fracturing technology. Shale gas technology tackling should be intensified supported in view of the national science and technology plan, such as special projects, funds etc., it is very importance to develop the key technologies and core equipment in the whole industry chain, closely combined with the technical problems in shale gas production, prospective technologies should be intensively researched and reserved in the process of shale gas development, the cost of shale gas development should be continued to decline in shale gas development by improving technical level, ensuring the benefit and sustainable development of shale gas industry.

\subsection{Optimizing Development Planning and Sequence of Shale Gas, Promoting Strategic EIA and Planning EIA}

It is imperative to investigate the land distribution of the shale gas resources before performing SEIA, it is necessary to carry out strategic environmental assessment and classify the types of shale gas resources according to the relevant environment protection requirements, further identifying the areas where are not suitable for development. Shale gas development should be supported and promoted in China. Shale gas development planning could be optimized in terms of resource and environmental efficiency, ecological environment carrying capacity and environmental risk level [15]. Comprehensively considering the regional environmental characteristics, the shale gas favorable areas can be classified, screened, optimizing of shale gas development sequence. The PEIA of key and pilot blocks should be accelerated in Ordos Basin, Sichuan, Chongqing, Guizhou, Hubei, Hunan and other regions. The environmental impact assessment can be involved in advance, measures should be taken to avoid and protect sensitive targets, optimizing the environmental impact of shale gas development in a large scale.

\subsection{Clarifying the Management Ideas and System of Environmental Impact Assessment (EIA) and Strengthen EIA Supervision}

The EIA management system of shale gas and other unconventional natural gas resource should be constantly improved, combined with the different grades of EIA and the classified management regulations. Environmental protection admittance requirements should be studied and formulated for shale gas exploration and development, strictly controlling EIA. The measures for the administration of shale gas development projects are formulated in different regions, combined with the results of SEIA and PEIA, as well as the environmental characteristics and sensitivity of different regions in China. The whole process supervision mechanism is established and improved according to the characteristics of shale gas rolling development, including PEIA, project EIA and three-simultaneity.

\subsection{Strengthening International Cooperation and Exchanges, Learning from Abroad Mature Experience}

At present, these countries, such as United States, Canada and other countries, with relatively mature mining technology, have achieved the commercial development of shale gas, and some enterprises have participated shale gas pilot development projects in China. The laws and regulations have special provisions on the special environmental problems caused by shale gas development in United States, and the environmental supervision requirements have also been more stringent in recent years. China should strengthen international cooperation, collect pollution control technology and pollution source data from the United States, Canada and other countries, learn from their environmental management experience. Referring to the characteristics of China's resources and environment, the environmental management regulations and technical specifications are scientifically formulated.

\subsection{Promoting Systems and Mechanisms Innovation}

Competitively transferring shale gas blocks and improving the shale gas block exit mechanism, the market was opened to introduce various investment entities, and market structure and market system was built for effective competition in the shale gas industry in order to increase investment in shale gas and reduce development costs, giving full play to the basic role of market forces in allocating resources. Joint venture and foreign cooperation should be encouraged to speed up the exploration and development of existing high-quality blocks. Market players could be actively cultivated, such as the technical services, the development of shale gas equipment manufacturing. The mechanism for technological exchange and cooperation can be further established in shale gas, the mechanisms for the regulation of shale gas market and environment could be improved.

\subsection{Intensifying Policy Support}

Implementing fiscal subsidies policy for the development and utilization of shale gas, the mining rights management system which is compatible with the rolling exploration and development of shale gas should be studied and established, policies is formulated to support the use of shale gas on the spot, the approval of overall development plans for shale gas cooperation projects with other countries simplified to arouse the enterprises' initiative. The local governments should actively support shale gas enterprises in land acquisition, urban and rural planning, environmental assessment and safety assessment, and social environment, and create a favorable external environment for the development of the shale gas industry. 


\section{Conclusion}

Shale gas is an important oil and gas resource, it can mitigate resource shortage, and it also faces with two challenges, first it consumes a huge amount of water resource, second it causes environmental pollution, both of which constraints the development of shale gas exploration. How to balance shale gas development and environmental protection, it needs more analysis and thinks, except it requires further assessment on the negative impact of shale gas development and its response to human life in the future. High-standard, strict requirements for management system was established from an administrative perspective, the top-level design of shale gas environmental regulation could be strengthened. Focusing on environmental impact characteristics, and highlighting environmental protection and shale gas monitoring. Technically, a large number of scientific researches and technical studies for the problem of shale gas development. Using its advanced research and development capabilities. To conduct coordinated, sustainable development, we should develop low investment, high yield and cleaner technology for shale gas development.

\section{References}

[1] Ma X. H. (2017). Natural gas and energy revolution case study of Sichuan-Chongqing gas province. Natural Gas Industry, 37 (1): $1-8$.

[2] Tong L., Zhang X. Z., Tian C. X., Liang P., Zhou X. S. (2013). Shale gas development in our country needs to improve environmental monitoring. Environmental Impact Assessment, 35 (1): 29-31.

[3] Wang X. Z., Zhang L. X., Gao C. (2016). The heterogeneity of shale gas reservoir in the Yanchang formation, Xiasiwan area, Ordos basin. Earth Science Frontiers, 2 (1): 134-145.

[4] Yu J., Qin R. B., Liu C. C., Chen G. H. (2017). Logging evaluation and production "sweet spot" identification of shale play: a case study on Eagle Ford shale play in the USA. China Petroleum Exploration, 22 (3): 104-112.

[5] Lester Y., Ferrer I., Thurman E. M., Sitterley K. A., Korak J. A., Aiken G., Linden K. G. (2015). Characterization of hydraulic fracturing flowback water in Colorado: Implications for water treatment. Science of the total environment, 512-513: 637-644.
[6] Zhang D. X, Yang T. Y. (2015). Environmental impacts of hydraulic fracturing in shale gas development in the United States. Petroleum Exploration and Development, 42 (6): 801-807.

[7] Yang H., Huang X. J., Yang Q. Y., Tu J. J., Li S. F., Yang D. M., Xia H., Flower R. J., Thompson J. R. (2015). Water requirements for shale gas fracking in Fuling, Chongqing, Southwest China. Energy Procedia, 76: 106-112.

[8] Zhang H., Zhang D. J., Lu P. L. (2017). Primary assessment of shallow ground water pollution risk for shale gas exploitation in Chongqing. Journal of Environmental Engineering, 11 (4): 2016-2024.

[9] Peng M., Chen J. X., Dong J. T., Liang H. (2017). Shale gas development regional disparity of water environment and the protection policy in China. Environmental Engineering, 35 (1): $151-154$.

[10] Digiulio D. C., Jackson R. B. (2016). Impact to underground sources of drinking water and domestic wells from production well stimulation and completion practices in the Pavillion, Wyoming, Field. Environmental science\& technology, 50 (8): 4524-4536.

[11] Harknessa J. S., Darrahb T. H., Warner N. R., Whyte C., J., Moore M. T., Millot R., Kloppmann W., Jackson R. B., Vengosh A. (2017). The geochemistry of naturally occurring methane and saline groundwater area of unconventional shale gas development. Geochimicaet cosmochimica acta, 208: 302-334.

[12] Jane L., Laura F., Corinne B., Jens B., Jens B., Scott P. An independent scientific assessment of well stimulation in California Volume II: potential environmental impacts of hydraulic fracturing and acid stimulation. 2015.

[13] EPA. Hydraulic fracturing for oil and gas: impacts from the hydraulic fracturing water cycle on drinking water resources in the United States (Appendices). 2016.

[14] Brantley S. L., Yoxtheimer D., Arjmand S., Grieve P., Vidic R., Pollak J., Liewellyn G. T., Abad J., Simon C. (2014). Water resource impacts during unconventional shale gas development: The Pennsylvania experience. International journal of coal geology, 126: 140-156.

[15] Niu H., Luo M., Jia Y. L., Zhuang S. Y., Liang R., Li W. (2017). Suggestions on environmental management for shale gas exploitation in China. Environmental Impact Assessment, 39 (3): $1-4$ 